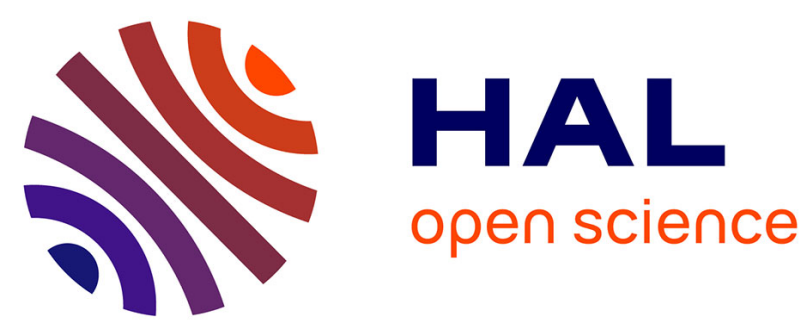

\title{
Humus structure during a spruce forest rotation: quantitative changes and relationship to soil biota
}

Matthieu Chauvat, Jean-François Ponge, Volkmar Wolters

\section{To cite this version:}

Matthieu Chauvat, Jean-François Ponge, Volkmar Wolters. Humus structure during a spruce forest rotation: quantitative changes and relationship to soil biota. European Journal of Soil Science, 2007, 58 (3), pp.625-631. 10.1111/j.1365-2389.2006.00847.x . hal-00495378v2

\section{HAL Id: hal-00495378 \\ https://hal.science/hal-00495378v2}

Submitted on 12 Aug 2010

HAL is a multi-disciplinary open access archive for the deposit and dissemination of scientific research documents, whether they are published or not. The documents may come from teaching and research institutions in France or abroad, or from public or private research centers.
L'archive ouverte pluridisciplinaire HAL, est destinée au dépôt et à la diffusion de documents scientifiques de niveau recherche, publiés ou non, émanant des établissements d'enseignement et de recherche français ou étrangers, des laboratoires publics ou privés. 


\title{
Humus structure during a spruce forest rotation: quantitative changes and relationship to soil biota
}

\author{
M. CHAUVAT ${ }^{\mathrm{a}}$, J. F. PONGE ${ }^{\mathrm{b}} \&$ V.WOLTERS ${ }^{\mathrm{a}}$
}

${ }^{\mathrm{a}}$ Justus Liebig University, Department of Animal Ecology, Heinrich-Buff-Ring 26-32, 35392 Giessen, Germany, and ${ }^{\mathrm{b}}$ Muséum National d'Histoire Naturelle, CNRS UMR 5176, 4 Avenue du Petit-Château, 91800 Brunoy, France

Correspondence: M. Chauvat. E-mail: matthieu.chauvat@bio.unigiessen.de

\section{Summary}

Temporal dynamics of edaphic communities affect numerous processes in forests and also strongly influence the soil's organic matter status. We have linked long-term changes in the formation of organic matter (using humus micromorphological analyses) to changes in the soil's community structure during a spruce forest cycle on acid soil. The study was carried out at four sites of different age-classes in the Tharandter forest, Germany. The composition of the deeper humus layers $(\mathrm{OH}, \mathrm{A})$ was stable. Herbaceous litter, recent spruce litter, fragmented spruce litter, decomposed litter and faeces and fungi, which contributed to the organic layer (OL and $\mathrm{OH}$ horizon), significantly changed during the forestry cycle, especially with the shift from the early stage to intermediate stages. Parallel changes of the faunal assemblage of the soil showed quantitative relations between major stages of the forest development, humus dynamics and soil community composition. The herbaceous litter was correlated with surface-dwelling Collembola and microbial properties with faeces and fungi. Our results suggest that the long-term stability of deep organic layers provides a refuge for decomposers and detritivores that allows a rapid response to both adverse and favourable conditions, taking place in OL and OF layers. Furthermore, the opening of the canopy in mature stands allows the decomposers to adapt to changes in resource input long before the collapse of the forest.

\section{Introduction}


The long-term dynamics of managed forest have been rarely considered in soil ecology. This is a serious shortcoming, because the temporal dynamics of edaphic communities affect numerous processes in forests (e.g. decomposition, nutrient release and respiration) and also have a strong influence on the organic matter in the soil (Wolters, 2000; Johnston \& Crossley, 2002). Moreover, most studies have focused either on soil processes (Ponge, 1999; Okland et al., 2003) or on the assemblages of soil organisms (Butterfield, 1999; Chauvat et al., 2003; Eaton et al., 2004), whereas few have considered both aspects simultaneously.

We have linked long-term changes in the formation of organic matter to changes in the soil's community structure during a cycle of a spruce forest on acid soil. We focused on the topsoil containing most of the organic matter. The simultaneous availability of four forest stands of different ages enabled us to apply the 'space for time' substitution approach as a surrogate for a long-term study on humus micromorphology and soil fauna (cf Pickett, 1989). Despite some methodological shortcomings, 'space for time' substitution is generally considered to be the only way of determining long-term changes in forest ecosystems (Trofymow \& Porter, 1998). Several authors (Bernier \& Ponge, 1994; Topoliantz et al., 2000; Davidson et al., 2004) have shown that by studying the morphological structure of the humus (e.g. description and classification of soil biogenic structures) they could get a direct insight into the status of the soil organic matter, performance of soil biota and growth conditions of plants. Availability of data on microarthropods and microflora recorded by Zaitsev et al. (2002) and Chauvat et al. (2003) parallel to the sampling of humus material will enable us to assess the relations between soil biota and humus dynamics by means of correlations. We have pursued this line of investigations by posing the following questions.

1 What are the humus components characterizing different successional stages in a spruce forest rotation?

2 Are changes in humus composition and structure systematically associated with changes in soil community structure and performance?

\section{Materials and methods}

Study sites

The study was carried out at four sites under secondary spruce forest (Picea abies [L.] Karst.) selected within the project FORCAST of the European Union. Each site covers approximately 4 ha. The sites are close to each other 
in the Tharandter forest $\left(50^{\circ} 58^{\prime} 00^{\prime \prime} \mathrm{N}, 13^{\circ} 34^{\prime} 16^{\prime \prime} \mathrm{E}\right), 20 \mathrm{~km}$ southwest of Dresden, at about $380 \mathrm{~m}$ above sea level. The climate there is humid oceanic with a mean annual precipitation of $820 \mathrm{~mm}$ and a mean annual temperature of $+7.5^{\circ} \mathrm{C}$. The sites represent four ages, namely 5, 25, 45 and 95 years. All stands had been planted on land from which a previous spruce stand had been clear-cut. We denote the four stands as $5 \mathrm{~S}, 25 \mathrm{~S}, 45 \mathrm{~S}$, and 95 S, respectively. The soil is a Dystric Cambisol in the FAO classification with a moder humus form. The mean $\mathrm{pH}$ (in water) of the organic layer varied between 3.6 at $25 \mathrm{~S}$ and 4.3 at $5 \mathrm{~S}$ (see Zaitsev et al., 2002 for a more detailed description of environmental features).

\section{Sampling of humus blocks}

Five $(25 \mathrm{~S}, 45 \mathrm{~S}, 95 \mathrm{~S})$ or four $(5 \mathrm{~S})$ subplots were identified at random at each site in October 2001. The soil was then sampled on them as described by Bernier \& Ponge (1994). Blocks of $25 \mathrm{~cm}^{2}$ surface area and $9 \mathrm{~cm}$ depth that included the whole organic layer (cf Zaitsev et al., 2002) were prepared directly in the field with a sharp knife. Each block was then separated into its constituent horizons: OL, OF, OH and A. Thick horizons (more than $1.5 \mathrm{~cm}$ ) were subdivided into several horizontal layers. The separated blocks were fixed in $95 \%$ ethanol in the field, and then transferred to the laboratory. We had a total of 111 humus samples.

\section{Humus analysis}

All humus samples were spread out in Petri dishes filled with $95 \%$ ethanol. The various solid organic components were identified under a dissecting microscope ( $\mathrm{x} 40$ ), and their relative area was quantified by the point-count method (Jongerius, 1963; Rozé , 1989). To do so, a transparent film with a 300-point grid was placed above each of the samples and all components falling below grid nodes were identified. Results are expressed as percentages of the area of each solid element. In all 62 humus components were identified.

\section{Data treatment and statistics}

We transformed the humus data by principal components analysis (PCA) to obtain an ordination of them. In a first PCA we used all humus components as active variables and all four horizons (OL, OF, OH and A) coded as 0 or 1 served as passive variables for interpreting the graphs without affecting the result. In view of the results of 
this first PCA, a reduced matrix of only humus components confined to OL and OF layers was again ordered by PCA. Data were standardized to means zero and to unit variance beforehand. Both PCAs were done on the correlations matrices.

A k-means clustering algorithm was then applied to correlation coefficients between the original variables and the new axes from the second PCA to group humus components of similar response patterns (cf Hartigan \& Wong, 1979). By doing this we aimed at reducing the numbers of variables by identifying consistent groups of humus components and so simplify further analyses. To determine the best value of k, i.e. the optimal number of clusters, the quality of the clustering (number and structure of the clusters) was assessed by the overall average silhouette coefficient, i.e. a measure of the strength of each object's membership to its cluster (Kaufman \& Rousseeuw, 1990). The silhouette coefficient Sc of a clustering is defined as the average silhouette of all objects as follows.

First define the silhouette of an individual object, $i$, as

$S_{i}=\left(b_{i}-a_{i}\right) / \max \left[a_{i}, b_{i}\right]$

where $a_{i}$ is the average distance in the vector space between object $i$ and all other objects in its cluster, say cluster A, and $b_{i}$ is the average distance between that same object and all objects in the nearest other cluster, say cluster B. The silhouette coefficient of the clustering is then

$S_{c}=1 / k \sum S_{i}$

Clearly, from Equation (1), the larger are the differences between $a_{i}$ and $b_{i}$ the larger is $S_{c}$ and the 'tighter' is the clustering, and the better is the classification in that sense.

Then, percentages of each humus component within an identified cluster or group were summed to obtain a single percentage value per group corresponding to its relative dominance in the $\mathrm{OL}+\mathrm{OF}$ matrix. The effect of the factor stand age on the contribution of each group to the OL+OF matrix was analysed by a one-way analysis of variance (ANOVA). Percentages were Arcsin transformed prior to the ANOVA to achieve approximate normality and homoscedasticity. Moreover, we compared the proportion of the variance accounted for by the classification using the quantity denoted $R_{\mathrm{c}}^{2}$ at each stand age and equal to:

$1-s^{2}{ }_{\mathrm{W}} / s_{\mathrm{T}}^{2}$, 
where $s_{\mathrm{W}}^{2}$ is the residual variance within groups and $s_{\mathrm{T}}^{2}$ is the total variance (Webster \& Oliver, 1990).

The availability of data from complementary studies (Zaitsev et al., 2002; Chauvat et al., 2003) allowed us to analyse relations between soil biota and groups of humus components. Data on soil biota were recorded at the same sites and subplots as those from which we took the humus blocks on three occasions (see Zaitsev et al., 2002; Chauvat et al., 2003 for further details). Means of the data from the three sampling dates were compared with the results of micromorphological analysis in the humus. We did so using Spearman rank correlations between collembolan life forms (epedaphic, hemiedaphic and euedaphic), oribatid feeding groups (fungivorous, herbifungivorous and omnivorous), microbial variables (microbial biomass and fungal biomass) (original data are available at http://www.unigiessen.de/tieroekologie/soil_biota/) and groups of humus components.

\section{Results}

The first PCA (Table 1) on humus data from all four horizons (111 samples, 62 humus components) revealed that only $\mathrm{OL}$ and $\mathrm{OF}$ layers discriminated between sites, whereas coordinates of $\mathrm{OH}$ and A layers were very close to the origin. This suggests a stable composition of deeper humus layers during a forestry cycle. It also indicates, however, that $\mathrm{OH}$ and $\mathrm{A}$ layers are not suited for evaluating the contribution of the various humus components to different stages of the rotation. We therefore did a second PCA confined to the cumulative results for OL and OF layers (19 samples, 47 humus components; Figure 1 and Table 2). Grouping of the correlation coefficients of the first two axes of this analysis by $k$-means clustering and according to the best overall average silhouette coefficient (0.78) revealed five groups. The contributions of the different humus components to each of these five groups are summarized in Table 3. We gave the groups associative names based on dominant humus components (excluding components with a contribution $<5 \%$ ). Group 1 is dominated by debris of herbaceous plants (> 85\%) and is thus referred to as 'herbaceous litter'. Most components of Group 2 relate to freshly fallen and slightly decomposed spruce litter (> 56\%, group name 'recent spruce litter'). Fragmented components of spruce litter characterize Group 3 (> 78\%, group name 'fragmented spruce litter') and strongly degraded litter components characterize Group 4 ( $>95 \%$, group name 'decomposed litter'). Finally, Group 5 mainly is a mix of faecal and fungal components (> 80\%, group name 'faeces and fungi').

Each of the five groups was affected by the factor 'stand age' and the proportion of the variance explained by differences between stands exceeds $50 \%$ whatever the group considered (Table 4). The share of 
'herbaceous litter' (Group 1) was much larger at $5 \mathrm{~S}$ than at all other sites (about 3.7 to 15 times), though it seems slightly to increase again at $95 \mathrm{~S}$ (Figure 2). The share of the group 'recent spruce litter' (Group 2) constantly increases from $5 \mathrm{~S}$ to $45 \mathrm{~S}$ (approximately triple) and then slightly decreases at $95 \mathrm{~S}$ to reach an intermediate value. Though the contribution of 'fragmented spruce litter' (Group 3) was small at all sites (< $10 \%$ ), it was larger at $5 \mathrm{~S}$ and $95 \mathrm{~S}$ than at $25 \mathrm{~S}$ and $45 \mathrm{~S}$. The share of 'decomposed litter' (Group 4) declined by a factor of approximately 3.2 after the clear-cut (from $95 \mathrm{~S}$ to $5 \mathrm{~S}$ ) and remained small at intermediate stages. 'Faeces and fungi' (Group 5) contributed 2.5 to 4 times more to humus components of intermediate stages than to that of $5 \mathrm{~S}$ and $95 \mathrm{~S}$ and were also approximately 1.3 times larger at $25 \mathrm{~S}$ than at $45 \mathrm{~S}$. A comparison of individual stages showed that 'herbaceous litter' significantly dominated at $5 \mathrm{~S}$, while 'faeces and fungi' followed by 'recent spruce litter' dominated at $25 \mathrm{~S}$ and $45 \mathrm{~S}$. The mature stand $(95 \mathrm{~S})$ is characterized by a shift from 'recent litter' to 'decomposed litter'.

Results of the correlations relating the five groups of humus components to functional groups of soil biota are summarized in Table 5. Few, but interesting, significant results were found. 'Faeces and fungi' (Group 5) was positively correlated with fungivorous oribatids (both browsers and grazers). 'Herbaceous litter' (Group 1) was positively correlated with epedaphic Collembola, whereas 'decomposed spruce litter' (Group 4) was negatively correlated with ergosterol content (as a measure of fungal biomass).

\section{Discussion and conclusions}

We believe that we have for the first time found evidence for quantitative relations between major stages of the forest development, humus dynamics and composition of the soils biological community. We cannot exclude that our approach is partly biased by pseudoreplication and thus admit that the data must be interpreted with great care. However, we agree with Oksanen (2001) that concern about pseudoreplication in ecological studies (e.g. Hurlbert, 1984) has led to 'unwarranted stigmatisation of a reasonable way to test predictions referring to large-scale systems'. In view of the selection of study sites, we are confident that the data allowed us to ascribe differences between plots as differences between stand ages.

The combination of PCA techniques with k-means clustering allowed us to identify humus groups dominating the uppermost layers of the spruce forest sequence: herbaceous litter, recent spruce litter, fragmented spruce litter and decomposed litter, as well as faeces and fungi. The contribution of these groups to the organic 
layer changed dramatically during a forest rotation. In particular, alterations associated with the shift from the early stage to intermediate stages of the forest confirm the humus layer to be a sensitive indicator of changes. Canopy closure, typically observed at intermediate stages, leads to large modifications of humus composition. Moreover, we have shown that dynamic changes of humus composition are significantly correlated with alterations in the structure of the soil community. The fact that these changes were confined to OL and OF layers suggests a long-lasting stability of the lower strata of the organic layer. It points to the role of deeper organic horizons as an important refuge for decomposers, allowing a delayed response of soil biota to vegetational changes or disturbance (e.g. Ruf, 2000). This conclusion is supported by our finding mineral-dominant enchytraeid faeces in the uppermost horizons of the final stage of the sequence. It points to important vertical movements of materials, even in mature stands.

The beginning of the forestry cycle is characterized by the addition of large amounts of herbaceous components to the uppermost horizons of the organic layer. Ground vegetation flourishes after clear-cutting. It also flourishes in gaps in the canopy (Collins \& Pickett, 1988). Gartner \& Cardon (2004) emphasize the important role of less-recalcitrant material in stimulating decomposers. Thus, the promotion of decomposition a few years after clear-cutting reported by various authors (Schulze et al., 2000; Law et al., 2001; Chauvat et al., 2003) could be explained partly by the priming effect of herbaceous litter. The increasing share of herbaceous components in the organic layer of the old stand (95 S) suggests that the rapid response of the decomposer community to the dramatic change induced by clear-cutting is facilitated by pre-adaptation long before the collapse of the forest ecosystem (Page, 1974; Bernier \& Ponge, 1994; Fons \& Klinka, 1998; Ruf, 2000). The fact that the collembolan assemblage at $95 \mathrm{~S}$ was more like that of $5 \mathrm{~S}$ than at $25 \mathrm{~S}$ or $45 \mathrm{~S}$ supports this hypothesis (Chauvat et al., 2003). It might also explain the similar findings of Loranger et al. (2001) for a mountainous spruce chronosequence.

A major shift in the state of the ecosystem occurs at intermediate stages of the forestry cycle, when canopy closure leads to increasing inputs of fresh spruce litter. Herbaceous litter declines, as the understory vegetation is suppressed by lack of light (Hunt et al., 2003). Though the quality of fresh spruce litter is poor (Harrison, 1971), the amount of invertebrate excrement considerably increases. The accumulation of faecal particles not only reflects the stimulation of consumers with forest growth, but also a delay in decomposition that is typical of moder soils (cf Ponge, 2003). Increasing amounts of hyphae indicate the initiation of further steps of the decomposer cascade, as fungi are well adapted for degrading recalcitrant organic matter in acid environments. The joint increase of invertebrate faeces and fungal components at $25 \mathrm{~S}$ and $45 \mathrm{~S}$ thus points to an 
important feedback among several groups of soil biota, with invertebrate consumers opening up new surfaces for microbial colonization and fungal pre-conditioning of litter, thereby increasing the accessibility of the organic matter to primary decomposers (Anderson \& Ineson, 1983; Heal et al., 1997). The accumulation of decomposed and fragmented spruce litter at $95 \mathrm{~S}$ shows a continuation of this process as the forest matures.

The correlative approach allowed us to relate humus composition dynamics to decomposer community structure. First, the positive correlation between 'herbaceous litter' and epedaphic Collembola points to the positive response of surface dwelling microarthropods to the rich source of food provided by the ground vegetation (Petersen, 2002). Second, the close associations between fungal biomass, fungivorous oribatids and faeces and fungi support the contention of the decomposer feedback loop outlined above (i.e. between microflora and faunal activity). This accords with the argument that changes of the resource might stimulate fungivorous oribatids (Behan-Pelletier, 1999). The negative association between fungal biomass and decomposed litter is biologically more difficult to interpret, and we can only speculate that the fungi do not like such poor quality substrate. Finally, the absence of a significant correlation between euedaphic Collembola and any group of humus components suggests that deep dwelling taxa are insensitive to changes taking place in uppermost parts of the organic layer. Euedaphic species can efficiently use the buffering capacity of deep organic layers as a result of both nutritional plasticity and metabolic activity (Petersen, 2002).

In conclusion, this study provides a concise framework for the factors characterizing the transformation of organic matter during a typical spruce forest rotation. Increased metabolic activity associated with the priming of decomposition processes by high quality litter leads to a rapid decline of strongly decomposed litter after clear-cutting. The long-term stability of deep organic layers seems to provide a refuge for decomposers that allows a rapid response to both adverse and favourable conditions in OL and OF layers, and the opening of the canopy of mature stands allows the decomposers to adapt to changes in resource input long before the forest collapses. This would also explain the surprisingly moderate response of the soil community to the dramatic changes taking place above ground (Zaitsev et al., 2002; Chauvat et al., 2003). Within this framework, the autocatalytic process of primary consumers, stimulating fungal decomposition and vice versa leads to an accumulation of faecal pellets at intermediate stages of forest succession. Higher levels of the decomposer food web respond differentially, with some microarthropod groups (life-form or feeding groups) favoured by increased availability of food, while others may suffer from modification of the topsoil organic layer. Fragmentation of litter, nevertheless, continues even after clearcutting, and the accumulation of litter debris 
beneath the oldest and youngest stands initiates the downward transport of organic matter into deeper layers of the humus profile.

\section{Acknowledgements}

This study was supported by the forest carbon and nitrogen trajectories (FORCAST) project funded by EU (contractEVK2-CT,1999-00035). We owe many thanks to members of the Department of Animal Ecology of Justus-Liebig-Universität, Giessen, for their support, especially Dr K. Ekschmitt, who gave us valuable statistical advice. We are grateful to two anonymous reviewers and to Dr R. Webster for helpful and constructive comments on a previous draft.

\section{References}

Anderson, J.M. \& Ineson, P. 1983. Interactions between soil arthropods and microorganisms in carbon, nitrogen and mineral element fluxes from decomposing leaf litter. In: Nitrogen as an Ecological Factor (eds J.A. Lee, S. MacNeill \& L.H. Morison), pp. 413-432. Blackwell Scientific Publications, Oxford.

Behan-Pelletier, V.M. 1999. Oribatid mite biodiversity in agroecosystems: role for bioindication. Agriculture, Ecosystems and Environment, 74, 411-423.

Bernier, N. \& Ponge, J.F. 1994. Humus form dynamics during the sylvogenetic cycle in a mountain spruce forest. Soil Biology and Biochemistry, 26, 183-220.

Butterfield, J. 1999. Changes in decomposition rates and Collembola densities during the forestry cycle in conifer plantations. Journal of Applied Ecology, 36, 92-100.

Chauvat, M., Zaitsev, A.S. \& Wolters, V. 2003. Successional changes of Collembola and soil microbiota during forest rotation. Oecologia, 137, 269-276.

Collins, B.S. \& Pickett, S.T.A. 1988. Demographic responses of herb layer species to experimental canopy gaps in a northern hardwoods forest. Journal of Ecology, 76, 437-450. 
Davidson, D.A., Bruneau, P.M.C., Grieve, I.C. \& Wilson, C.A. 2004. Micromorphological assessment of the effect of liming on faunal excrement in an upland grassland soil. Applied Soil Ecology, 26, 169-177.

Eaton, R.J., Barbercheck, M., Buford, M. \& Smith, W. 2004. Effects of organic matter removal, soil compaction, and vegetation control on Collembolan populations. Pedobiologia, 48, 121-128.

Fons, J. \& Klinka, K. 1998. Temporal variations of forest floor properties in the Coastal Western Hemlock zone of southern British Columbia. Canadian Journal of Forest Research, 28, 582-590.

Gartner, T.B. \& Cardon, Z.G. 2004. Decomposition dynamics in mixed-species leaf litter. Oikos, 104, $230-246$.

Harrison, A.F. 1971. The inhibitory effect of oak leaf litter tannins on the growth of fungi, in relation to litter decomposition. Soil Biology and Biochemistry, 3, 167-172.

Hartigan, J.A. \& Wong, M.A. 1979. A K-means clustering algorithm. Applied Statistics, 28, 100-108.

Heal, O.W., Anderson, J.M. \& Swift, M.J. 1997. Plant litter quality and decomposition: an historical overview. In: Driven by Nature — Plant Litter Quality and Decomposition (eds G. Cadisch \& K.E. Giller), pp. 330. CAB International, Wallingford.

Hunt, S.L., Gordon, A.M., Morris, D.M. \& Marek, G.T. 2003. Understory vegetation in northern Ontario jack pine and black spruce plantations: 20-year successional changes. Canadian Journal of Forest Research, 33, 1791-1803.

Hurlbert, S.H. 1984. Pseudoreplication and the design of ecological field experiments. Ecological Monographs, $54,187-211$.

Johnston, J.M. \& Crossley, D.A. 2002. Forest ecosystem recovery in the southeast US: soil ecology as an essential component of ecosystem management. Forest Ecology and Management, 155, 187-203.

Jongerius, A. 1963. Optic-volume tric measurements on some humus forms. In: Soil Organisms (eds J. Doeksen \& J. van der Drift), pp. 137-148. North-Holland, Amsterdam.

Kaufman, L. \& Rousseeuw, P.J. 1990. Finding Groups in Data. An Introduction to Cluster Analysis. John Wiley \& Sons, New York. 
Law, B.E., Thornton, P.E., Irvine, J., Anthoni, P.M. \& van Tuyl, S. 2001. Carbon storage and fluxes in ponderosa pine forests at different developmental stages. Global Change Biology, 7, 755-777.

Loranger, G., Bandyopadhyaya, I., Razaka, B. \& Ponge, J.-F. 2001. Does soil acidity explain altitudinal sequences in collembolan communities? Soil Biology and Biochemistry, 33, 381-393.

Okland, T., Rydgren, K., Okland, R.H., Storaunet, K.O. \& Rolstad, J. 2003. Variation in environmental conditions, understorey species number, abundance and composition among natural and managed Picea-abies forest stands. Forest Ecology and Management, 177, 17-37.

Oksanen, L. 2001. Logic of experiments in ecology: is pseudoreplication a pseudoissue? Oikos, 94, 27-38.

Page, G. 1974. Effects of Forest Cover on the Properties of some Newfoundland Forest Soils. Publication No 1332. Canadian Forestry Service, Department of the Environment, Ottawa.

Petersen, H. 2002. General aspects of collembolan ecology at the turn of the millennium. Pedobiologia, 46, 246260.

Pickett, S.T.A. 1989. Space-for-time substitution as an alternative to long term studies. In: Long Term Studies in Ecology (ed. G.E. Likens), pp. 110-135. Springer, New York.

Ponge, J.-F. 1999. Horizons and humus forms in beech forests of the Belgian Ardennes. Soil Science Society of America Journal, 63, 1888-1901.

Ponge, J.-F. 2003. Humus forms in terrestrial ecosystems: a framework to biodiversity. Soil Biology and Biochemistry, 35, 935-945.

Rozé, F. 1989. Mise au point d'une méthode d'échantillonnage par points pour l'interprétation de lames minces: application à la comparaison de deux humus de landes après incendie. Revue d’Écologie et de Biologie du Sol, 26, 189-196.

Ruf, A. 2000. The long-term memory of soils: soil microarthropods in forest sites with different land use history. In: Abstract $-13^{\text {th }}$ International Colloquium on Soil Zoology (ed. J. Rusek), p. 190. Icaris Ltd, Prague.

Schulze, E.-D., Wirth, C. \& Heimann, M. 2000. Managing forests after Kyoto. Science, 289, 2058-2059. 
Topoliantz, S., Ponge, J.-F. \& Viaux, P. 2000. Earthworm and enchytraeid activity under different arable farming systems, as exemplified by biogenic structures. Plant and Soil, 225, 39-51.

Trofymow, J.A. \& Porter, G.L. 1998. Introduction to the coastal forest chronosequence project. In: Proceedings of a Workshop on Structure, Process, and Diversity in Successional Forests of Coastal British Columbia, Victoria, British Columbia (eds J.A. Trofymow \& A. MacKinnon), pp. 4-8. Northwest Science, Volume 72. Washington State University Press, Washington.

Webster, R. \& Oliver, M.A. 1990. Statistical Methods in Soil and Land Resource Survey. Oxford University Press, Oxford.

Wolters, V. 2000. Invertebrate control of soil organic matter stability. Biology and Fertility of Soils, 31, 1-19.

Zaitsev, A.S., Chauvat, M., Pflug, A. \& Wolters, V. 2002. Oribatid mite diversity and community dynamics in a spruce chronosequence. Soil Biology and Biochemistry, 34, 1919-1927. 


\section{Legends of figures}

Figure 1 PCA ordination of the 47 categories of humus components found in the OL and OF horizons in a chronosequence of four spruce stands showing the five groups identified by $k$-means clustering and the silhouette coefficient procedure. For explanations of codes see Table 3.

Figure 2 Means and standard errors of the contribution of each identified structural group of humus components to the whole humus composition in the $\mathrm{OL}+\mathrm{OF}$ layer at each site of our spruce chronosequence. 
Table 1 Eigenvalues of the correlation matrix and related statistics of the four components of the principal component analysis on the full data set of humus components found within four horizons (OL, OF, OH and A) across four stages $(5,25,45$ and 95$)$ of a spruce forest

\begin{tabular}{lllll}
\hline Order & Eigenvalue & $\begin{array}{l}\text { Percentage of } \\
\text { explained variance }\end{array}$ & $\begin{array}{l}\text { Cumulative } \\
\text { eigenvalues }\end{array}$ & $\begin{array}{l}\text { Cumulative } \\
\text { percentage of } \\
\text { explained variance }\end{array}$ \\
\hline 1 & 8.34 & 13.45 & 8.34 & 13.45 \\
2 & 5.05 & 8.15 & 13.39 & 21.60 \\
3 & 4.65 & 7.50 & 18.04 & 29.10 \\
4 & 3.55 & 5.73 & 21.59 & 34.83 \\
\hline
\end{tabular}


Table 2 Eigenvalues of the correlation matrix and related statistics of the two components of the principal component analysis on the reduced data set of only humus components confined to OL + OF horizons across four stages $(5,25,45$ and 95$)$ of a spruce forest

\begin{tabular}{lllll}
\hline Order & Eigenvalue & $\begin{array}{l}\text { Percentage of } \\
\text { explained variance }\end{array}$ & $\begin{array}{l}\text { Cumulative } \\
\text { eigenvalues }\end{array}$ & $\begin{array}{l}\text { Cumulative } \\
\text { percentage of } \\
\text { explained variance }\end{array}$ \\
\hline 1 & 10.09 & 21.93 & 10.09 & 21.93 \\
2 & 6.39 & 13.89 & 16.48 & 35.82 \\
3 & 5.57 & 12.11 & 22.06 & 47.93 \\
4 & 3.91 & 8.51 & 25.97 & 56.44 \\
\hline
\end{tabular}


Table 3 List and codes of humus components in the OL and OF horizons in four spruce stands. Components are classified into five groups relating to their PCA coordinates as analysed by the $k$-means clustering procedure. Components with a contribution less than $5 \%$ are indicated in parenthesis

\begin{tabular}{|c|c|c|}
\hline Code & Classes & Contribution to the group (\%) \\
\hline \multicolumn{3}{|c|}{ Group 1: Herbaceous litter } \\
\hline 60 & Herbaceous plant component & 31.9 \\
\hline 38 & Herbaceous components compacted in pellet & 26.6 \\
\hline 62 & Fragmented herbaceous plant component & 14.1 \\
\hline 59 & Fragmented herbaceous root & 13.4 \\
\hline 43 & Millipede faeces & 8.9 \\
\hline \multicolumn{3}{|c|}{ (55 Undetermined plant fragment) } \\
\hline \multicolumn{3}{|c|}{ (42 Holorganic enchytraeid faeces) } \\
\hline \multicolumn{3}{|c|}{ Group 2: Recent spruce litter } \\
\hline 57 & Unidentifiable spruce component & 21.5 \\
\hline 11 & Slightly broken grey spruce needle & 17.2 \\
\hline 3 & Orange entire spruce needle + white mycelium & 14.6 \\
\hline 14 & Spruce bark & 7.3 \\
\hline 26 & Hemorganic aggregate & 6.6 \\
\hline 1 & Bleached entire spruce needle & 6.1 \\
\hline 8 & Brown entire spruce needle + black mycelium & 6.0 \\
\hline 7 & Brown entire spruce needle + white mycelium & 5.0 \\
\hline \multicolumn{3}{|c|}{ (18 Central cylinder of spruce needle) } \\
\hline \multicolumn{3}{|c|}{ (6 Brown entire spruce needle) } \\
\hline \multicolumn{3}{|c|}{ (33 Fine hemorganic particle) } \\
\hline \multicolumn{3}{|c|}{ (47 Collembola faeces) } \\
\hline \multicolumn{3}{|c|}{ (29 Fine mineral particle) } \\
\hline \multicolumn{3}{|c|}{ (28 Mineral-dominant aggregate) } \\
\hline \multicolumn{3}{|c|}{ Group 3: Fragmented spruce litter } \\
\hline 23 & Fragmented spruce root & 34.9 \\
\hline 5 & Fragmented orange spruce needle & 31.8 \\
\hline 45 & Fragments compacted by earthworms & 14.7 \\
\hline 16 & Fragmented spruce twig & 10.9 \\
\hline 56 & Undetermined fragmented leaf & 5.1 \\
\hline \multicolumn{3}{|c|}{ (17 Spruce cone scale) } \\
\hline \multicolumn{3}{|c|}{ Group 4: Decomposed litter } \\
\hline 9 & Brown spruce needle particle & 19.6 \\
\hline 27 & Organo-dominant aggregate & 18.0 \\
\hline 30 & Organo-dominant mass & 13.3 \\
\hline 13 & Decomposed spruce male flower scale & 12.9 \\
\hline 41 & Mineral dominant enchytraeid faeces & 12.3 \\
\hline 19 & Spruce cone scale particle & 10.9 \\
\hline 12 & Spruce male flower scale & 8.4 \\
\hline \multicolumn{3}{|c|}{ (2 Fragmented bleached spruce needle) } \\
\hline \multicolumn{3}{|c|}{ Group 5: Faeces and fungi } \\
\hline 40 & Hemorganic enchytraeid faeces & 26.7 \\
\hline 39 & Organo-dominant faecal mass & 13.1 \\
\hline 34 & White mycelium & 12.4 \\
\hline 4 & Black mycelium & 8.9 \\
\hline 44 & Oribatid faeces & 7.5 \\
\hline 15 & Spruce twig & 6.0 \\
\hline 32 & Hemorganic mass & 5.9 \\
\hline 35 & Brown mycelium & 5.8 \\
\hline 10 & Grey entire spruce needle & 5.5 \\
\hline 24 & Mosses part & 5.4 \\
\hline \multicolumn{3}{|c|}{ (37 Mycorrhizas) } \\
\hline$(25 \mathrm{Fr}$ & nented mosses part) & \\
\hline
\end{tabular}


Table 4 Summary of ANOVA results $(F)$ for the effect of stand age on the contribution (in arc-sin of percentage) of groups of humus components to the $\mathrm{OL}+\mathrm{OF}$ horizons and values of the complement of relative variance $\left(R_{\mathrm{c}}^{2}\right)$. d.f. $=$ degrees of freedom

\begin{tabular}{llll}
\hline & \multicolumn{3}{c}{ Stand age } \\
\cline { 2 - 4 } & $F$ & d.f. & $R_{\mathrm{c}}^{2}$ \\
\hline Herbaceous litter (Group 1) & 48.6 & 3 & 0.89 \\
Recent spruce litter (Group 2) & 10.5 & 3 & 0.62 \\
Fragmented spruce litter (Group 3) & 26.6 & 3 & 0.81 \\
Decomposed litter (Group 4) & 22.9 & 3 & 0.79 \\
Faeces and fungi (Group 5) & 48.6 & 3 & 0.89 \\
\hline
\end{tabular}


Table 5 Spearman rank order correlation coefficients between humus components groups and functional groups of fauna and microbial parameters. Values of $\mathrm{R}$ of only significant results at the 5\% level after Bonferroni's adjustment are shown

\begin{tabular}{lccc}
\hline & $\begin{array}{c}\text { Herbaceous litter } \\
\text { (Group 1) }\end{array}$ & $\begin{array}{c}\text { Decomposed litter } \\
\text { (Group 4) }\end{array}$ & $\begin{array}{c}\text { Faeces and fungi } \\
\text { (Group 5) }\end{array}$ \\
\hline Epedaphic Collembola & 0.696 & & 0.758 \\
Fungivorous Oribatida & & & 0.667 \\
Fungal biomass (Ergosterol content) & & -0.702 & \\
\hline
\end{tabular}




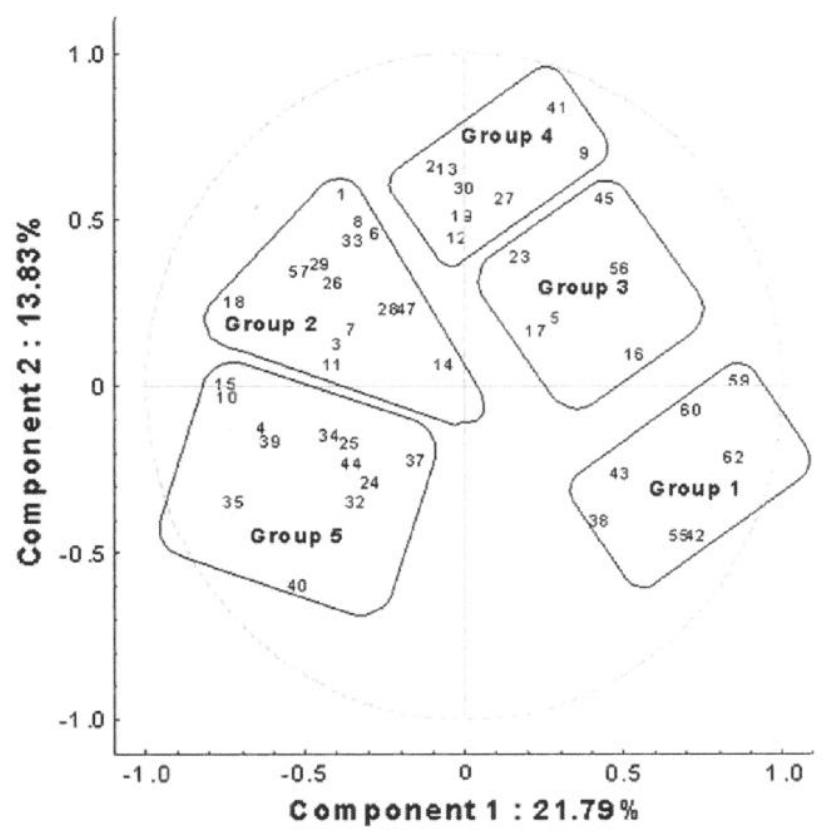

Fig. 1 


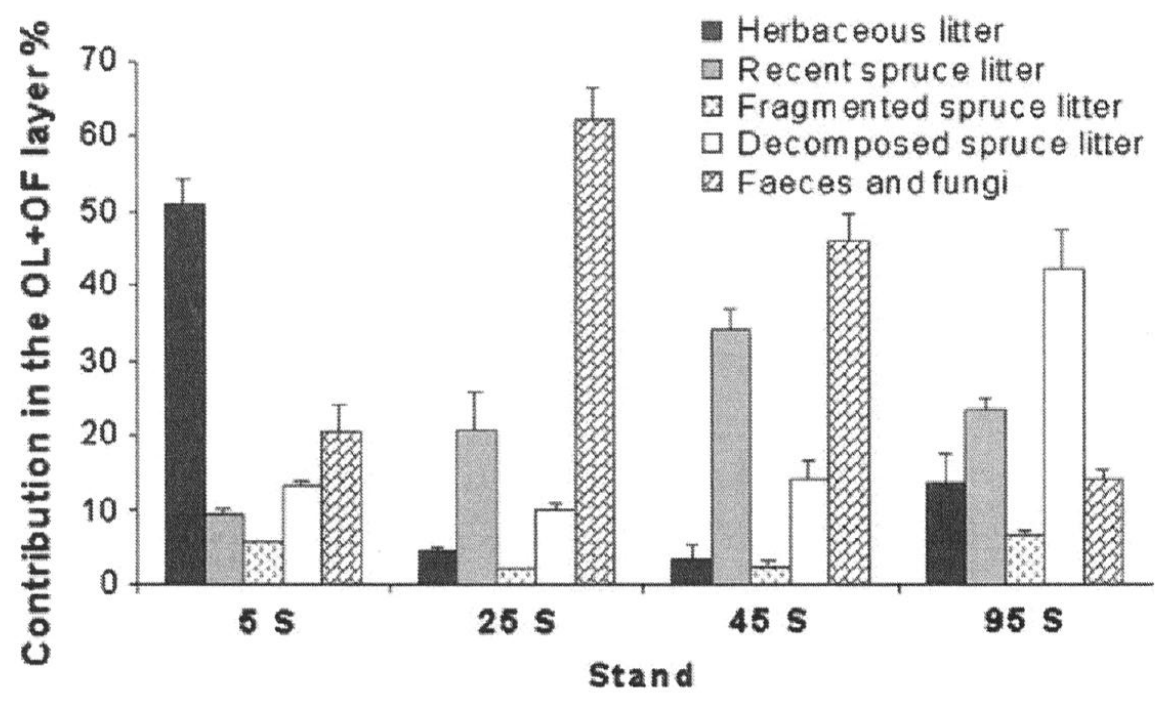

Fig. 2 